\title{
Microwave Radiometer Handbook
}

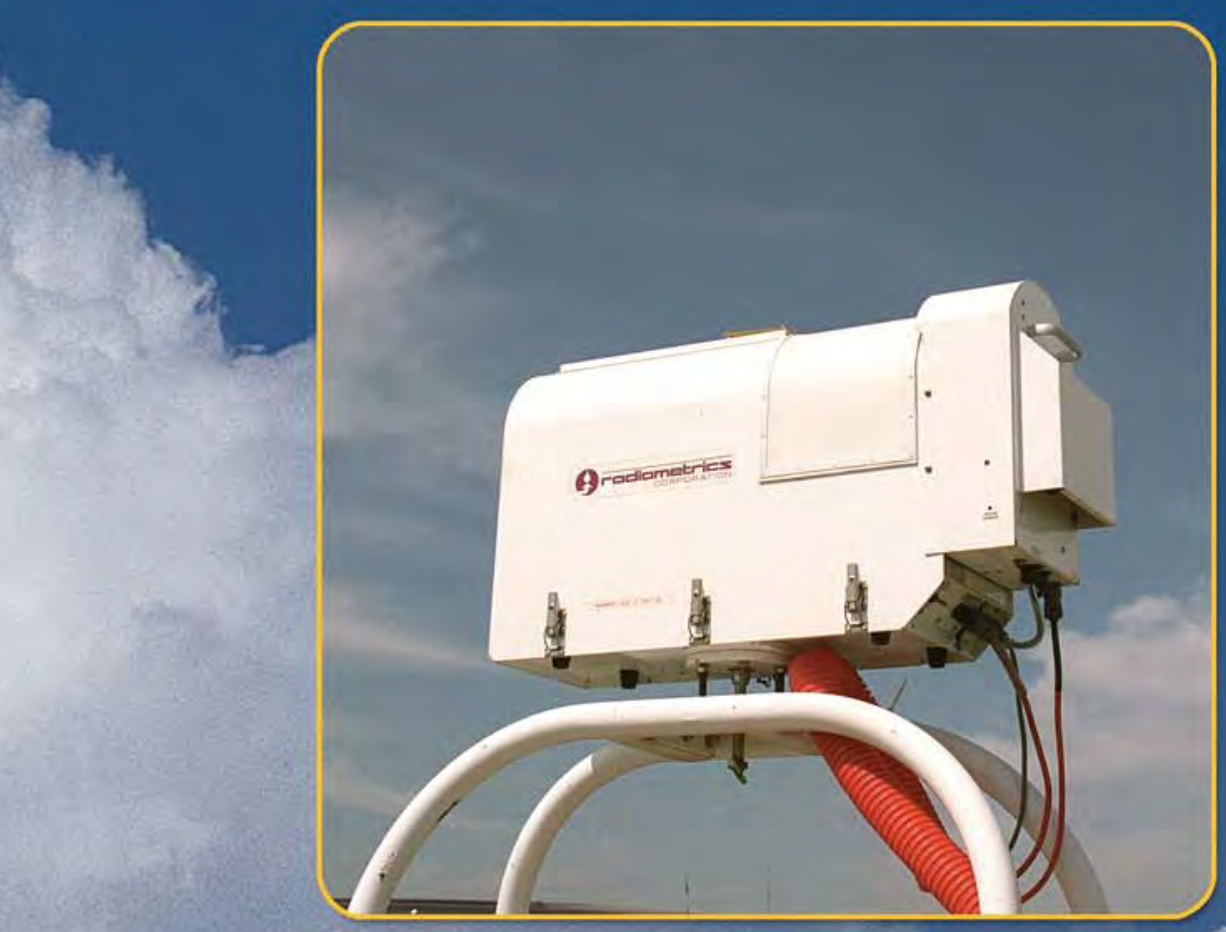

August 2006

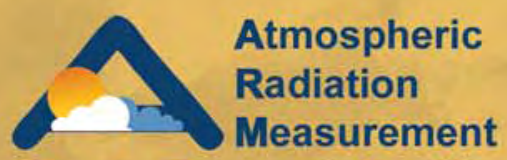

Climate Research Facility

U.S. Department of Energy 


\section{Microwave Radiometer (MWR) Handbook}

August 2006

V. R. Morris

Work supported by the U.S. Department of Energy, Office of Science, Office of Biological and Environmental Research 


\section{Contents}

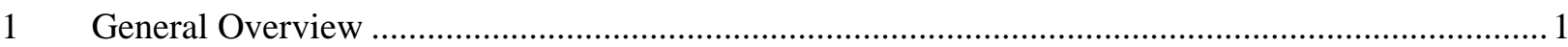

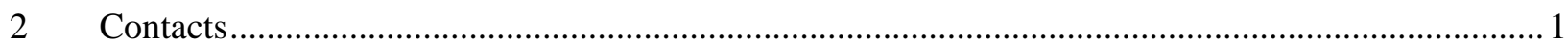

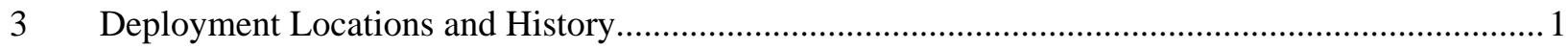

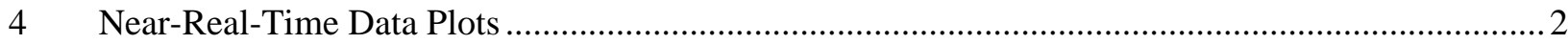

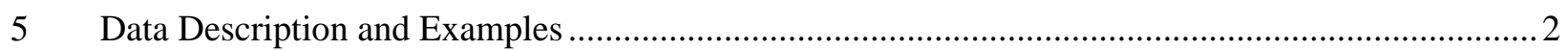

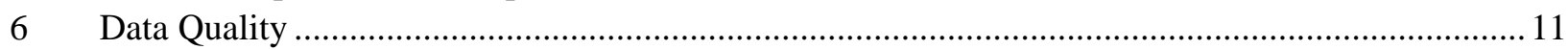

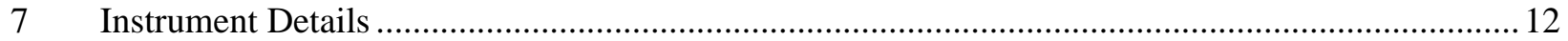

Figures

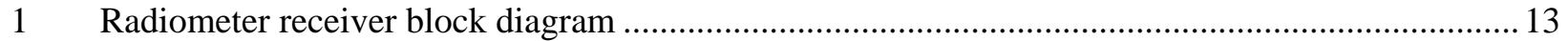

\section{Tables}

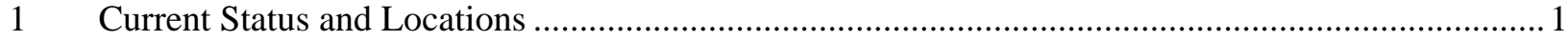

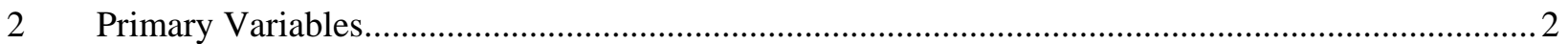

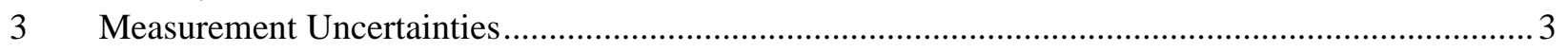

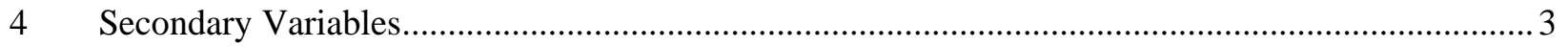

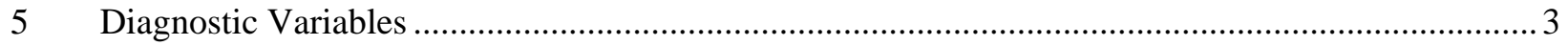

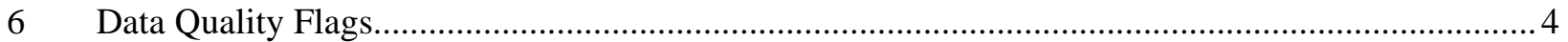

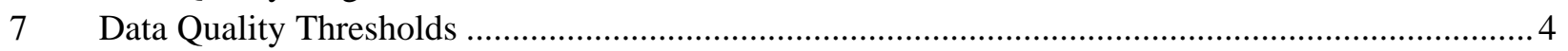

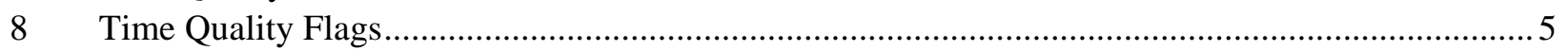

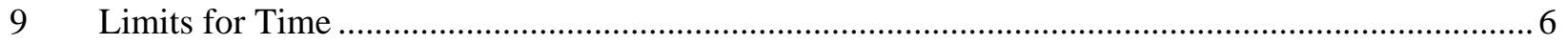

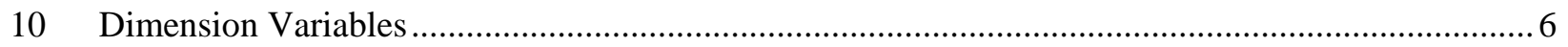

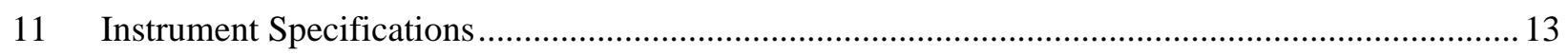




\section{General Overview}

The Microwave Radiometer (MWR) provides time-series measurements of column-integrated amounts of water vapor and liquid water. The instrument itself is essentially a sensitive microwave receiver. That is, it is tuned to measure the microwave emissions of the vapor and liquid water molecules in the atmosphere at specific frequencies.

\section{Contacts}

\subsection{Mentor}

Marie Cadeddu

Argonne National Laboratory

9700 S. Cass Avenue

Argonne, Illinois 60439

Phone: 630-252-7408

mcadeddu@anl.gov

\subsection{Instrument Developer}

Radiometrics Corporation

2840 Wilderness Place, Unit G

Boulder, Colorado 80301-5414

Phone: 303-449-9192

Fax: 303-786-9343

Website: www.radiometrics.com

\section{Deployment Locations and History}

Table 1. Current Status and Locations

\begin{tabular}{|c|c|c|c|c|}
\hline $\begin{array}{c}\text { Serial } \\
\text { Number }\end{array}$ & $\begin{array}{c}\text { Property } \\
\text { Number }\end{array}$ & Location & $\begin{array}{c}\text { Installation } \\
\text { Date }\end{array}$ & Status \\
\hline 4 & WD06605 & SGP/EF14 & $2004 / 06 / 24$ & operational \\
\hline 10 & WD11023 & SGP/CF1 & $1993 / 12 / 13$ & operational \\
\hline 11 & WD14131 & SGP/BF1 & $1993 / 12 / 13$ & operational \\
\hline 12 & WD14132 & SGP/BF5 & $1993 / 12 / 13$ & operational \\
\hline 15 & WD14869 & TWP/CF2 & $1998 / 11 / 12$ & operational \\
\hline 16 & WD13409 & TWP/CF1 & $1996 / 09 / 23$ & operational \\
\hline 17 & WD13410 & TWP/CF3 & $2002 / 02 / 27$ & operational \\
\hline 18 & WD12906 & SGP/BF6 & $1995 / 06 / 27$ & operational \\
\hline 20 & WD24769 & NSA/CF1 & $1997 / 02 / 28$ & operational \\
\hline 21 & WD24770 & NSA/CF2 & $1999 / 05 / 20$ & operational \\
\hline 33 & WD23179 & AMF & $2004 / 09 / 02$ & operational \\
\hline 38 & WD30750 & SGP/BF4 & $2004 / 09 / 02$ & operational \\
\hline
\end{tabular}




\section{Near-Real-Time Data Plots}

\section{MWR Data Plots.}

\section{Data Description and Examples}

Available data plots and other data products.

\subsection{Data File Contents}

Datastreams produced by the MWR that are available from the ARM Archive:

- mwrlos - water liquid \& vapor along line of sight (LOS) path

- mwrtip - brightness temperatures along tipping (TIP) curve airmasses.

\subsubsection{Primary Variables and Expected Uncertainty}

The MWR receives microwave radiation from the sky at $23.8 \mathrm{GHz}$ and $31.4 \mathrm{GHz}$. These two frequencies allow simultaneous determination of water vapor and liquid water burdens along a selected path. Atmospheric water vapor observations are made at the "hinge point" of the emission line where the vapor emission does not change with altitude (pressure). Cloud liquid in the atmosphere emits in a continuum that increases with frequency, dominating the $31.4 \mathrm{GHz}$ observation, whereas water vapor dominates the 23.8-GHz channel. The water vapor and liquid water signals can, therefore, be separated by observing at these two frequencies.

Table 2. Primary Variables

\begin{tabular}{|l|l|c|}
\hline Variable Name & \multicolumn{1}{|c|}{ Quantity Measured } & Unit \\
\hline tbsky23 & 23.8 GHz sky brightness temperature & $\mathrm{K}$ \\
\hline tbsky31 & 31.4 GHz sky brightness temperature & $\mathrm{K}$ \\
\hline vap & Total water vapor along LOS path & $\mathrm{cm}$ \\
\hline liq & Total liquid water along LOS path & $\mathrm{cm}$ \\
\hline sky_ir_temp & IR Brightness Temperature & $\mathrm{K}$ \\
\hline tbsky23tip & 23.8 GHz sky brightness temperature derived from tip curve & $\mathrm{K}$ \\
\hline tbsky31tip & 31.4 GHz sky brightness temperature derived from tip curve & $\mathrm{K}$ \\
\hline & $\begin{array}{l}\text { Total water vapor along zenith path using tip-derived brightness } \\
\text { temperatures }\end{array}$ & $\mathrm{cm}$ \\
\hline vaptip & $\begin{array}{l}\text { Total liquid water along zenith path using tip-derived brightness } \\
\text { temperatures }\end{array}$ & $\mathrm{cm}$ \\
\hline
\end{tabular}




\subsubsection{Definition of Uncertainty}

Table 3. Measurement Uncertainties

\begin{tabular}{|l|c|}
\hline \multicolumn{1}{|c|}{ Measurement } & Uncertainty \\
\hline Sky & $0.018 \mathrm{~K}$ \\
\hline Blackbody & $0.12 \mathrm{~K}$ \\
\hline Blackbody+noise & $\sim 0.15 \mathrm{~K}$ \\
\hline Gain reference & $\sim 0.02 \mathrm{~K}$ \\
\hline Receiver gain & $\sim 0.09 \mathrm{~K}$ \\
\hline Receiver offset & $0.035 \mathrm{~K}$ \\
\hline
\end{tabular}

\subsubsection{Secondary/Underlying Variables}

Table 4. Secondary Variables

\begin{tabular}{|l|l|c|}
\hline \multicolumn{1}{|c|}{ Variable Name } & \multicolumn{1}{|c|}{ Quantity Measured } & Unit \\
\hline time & Time offset from midnight & seconds \\
\hline tnd23 & Noise injection temp at 23.8 GHz adjusted to tkbb & $\mathrm{K}$ \\
\hline bb23 & $23.8 \mathrm{GHz}$ Blackbody signal & count \\
\hline bbn23 & $23.8 \mathrm{GHz}$ blackbody+noise injection signal & count \\
\hline sky23 & $23.8 \mathrm{GHz}$ sky signal & count \\
\hline tnd31 & Noise injection temp at 31.4 GHz adjusted to tkbb & $\mathrm{K}$ \\
\hline bb31 & $31.4 \mathrm{GHz}$ Blackbody signal & count \\
\hline bbn31 & $31.4 \mathrm{GHz}$ blackbody+noise injection signal & count \\
\hline sky31 & $31.4 \mathrm{GHz}$ sky signal & count \\
\hline actaz & Actual Azimuth & deg \\
\hline actel & Actual elevation angle & deg \\
\hline tipsky23 & $23.8 \mathrm{GHz}$ sky signal & count \\
\hline tipsky31 & $31.4 \mathrm{GHz}$ sky signal & Count \\
\hline tnd23I & Noise injection temp at 23.8 GHz derived from this tip & $\mathrm{K}$ \\
\hline tnd31I & Noise injection temp at 31.4 GHz derived from this tip & $\mathrm{K}$ \\
\hline
\end{tabular}

\subsubsection{Diagnostic Variables}

Table 5. Diagnostic Variables

\begin{tabular}{|l|l|l|}
\hline Variable Name & \multicolumn{1}{|c|}{ Quantity Measured } & \multicolumn{1}{c|}{ Unit } \\
\hline time_offset & Time offset from base_time & seconds \\
\hline tknd & Noise diode mount temperature & K \\
\hline tkxc & Mixer kinetic (physical) temperature & K \\
\hline tkbb & Blackbody kinetic temperature & K \\
\hline tkair & Ambient temperature & K \\
\hline wet_window & Water on Teflon window (1=WET, $0=$ DRY) & unitless \\
\hline tnd_nom23 & Noise injection temp at nominal temperature at $23.8 \mathrm{GHz}$ & $\mathrm{K}$ \\
\hline tnd_nom31 & Noise injection temp at nominal temperature at $31.4 \mathrm{GHz}$ & $\mathrm{K}$ \\
\hline
\end{tabular}


Table 5. (cont'd)

\begin{tabular}{|l|l|l|}
\hline Variable Name & \multicolumn{1}{|c|}{ Quantity Measured } & \multicolumn{1}{c|}{ Unit } \\
\hline tc23 & Temperature correction coefficient at 23.8 GHz & K/K \\
\hline tc31 & Temperature correction coefficient at 31.4 GHz & K/K \\
\hline r23 & $23.8 \mathrm{GHz}$ goodness-of-fit coefficient & unitless \\
\hline r31 & $31.4 \mathrm{GHz}$ goodness-of-fit coefficient & Unitless \\
\hline
\end{tabular}

\subsubsection{Data Quality Flags}

Most fields contain a corresponding, sample by sample, automated quality check field in the b1 level datastreams. These flags are named qc_<fieldname>. For example, the tknd field also has a companion qc_tknd field. Possible values for each sample of the $\mathbf{q c} \_<$fieldname $>$are shown in the table below.

Table 6. Data Quality Flags

\begin{tabular}{|c|l|}
\hline Value & \multicolumn{1}{|c|}{ Definition } \\
\hline 0 & All QC checks passed \\
\hline 1 & Sample contained 'missing data' value \\
\hline 2 & Sample was less than prescribed minimum value \\
\hline 3 & Sample failed both 'missing data' and minimum value checks \\
\hline 4 & Sample greater than prescribed maximum value \\
\hline 5 & Sample failed both minimum and maximum value checks (highly unlikely) \\
\hline 7 & Sample failed minimum, maximum and missing value checks (highly unlikely) \\
\hline 8 & $\begin{array}{l}\text { Sample failed delta check (change between this sample and previous sample } \\
\text { exceeds a prescribed value }\end{array}$ \\
\hline 9 & Sample failed delta and missing data checks \\
\hline 10 & Sample failed minimum and delta checks \\
\hline 11 & Sample failed minimum, delta and missing value checks \\
\hline 12 & Sample failed maximum and delta checks \\
\hline 14 & Sample failed minimum, maximum and delta checks \\
\hline 15 & Sample failed minimum, maximum, delta and missing value checks \\
\hline
\end{tabular}

The minimum and maximum thresholds are currently defined as follows:

Table 7. Data Quality Thresholds

\begin{tabular}{|l|l|l|l|l|}
\hline \multicolumn{1}{|c|}{$\begin{array}{c}\text { Field } \\
\text { Name }\end{array}$} & Units & \multicolumn{1}{c|}{ Min } & Max & \multicolumn{1}{c|}{ Delta } \\
\hline tknd & K & 303 & 333 & N/A \\
\hline tkxc & K & 303 & 333 & 0.5 \\
\hline tkbb & K & 250 & 320 & 1 \\
\hline tkair & K & 253 & 323 & N/A \\
\hline tnd23 & K & 163 & 353 & N/A \\
\hline
\end{tabular}


Table 7. (cont'd)

\begin{tabular}{|l|l|l|l|l|}
\hline \multicolumn{1}{|c|}{$\begin{array}{c}\text { Field } \\
\text { Name }\end{array}$} & Units & \multicolumn{1}{c|}{ Min } & Max & \multicolumn{1}{c|}{ Delta } \\
\hline bb23 & counts & 0 & N/A & N/A \\
\hline bbn23 & counts & 0 & N/A & N/A \\
\hline sky23 & counts & 0 & N/A & N/A \\
\hline tbsky23 & K & 2.73 & 100 & 0.01 \\
\hline tnd31 & K & 163 & 353 & N/A \\
\hline bb31 & counts & 0 & N/A & N/A \\
\hline bbn31 & counts & 0 & N/A & N/A \\
\hline sky31 & counts & 0 & N/A & N/A \\
\hline tbsky31 & K & 2.73 & 100 & 0.01 \\
\hline vap & cm & 0. & N/A & N/A \\
\hline liq & cm & $-3 *$ rms (see note 1) & N/A & N/A \\
\hline sky_ir_temp & K & 213 & 313 & 50 \\
\hline wet_window & unitless & (see note 2) & N/A & N/A \\
\hline tnd_nom23 & K & 163 & 353 & 80 \\
\hline tnd_nom31 & K & 163 & 353 & 80 \\
\hline tc23 & K/K & N/A & N/A & N/A \\
\hline tc31 & K/K & N/A & N/A & N/A \\
\hline
\end{tabular}

Note 1: rms is liquid_retrieval_rms_accuracy

Note 2: A value of 1 for the wet_window field means that the heater was $\mathrm{ON}$ at the time the sample was taken.

Additional information may be found at MWR Data Object Design for ARM netCDF file header descriptions.

In addition to the above data quality checks, the qc_time field is also supplied. The purpose of the qc_time field is to help detect duplicate samples, missing samples or other sample time problems. The qc_time field contains a value for each sample time. Refer to the table below for details.

Table 8. Time Quality Flags

\begin{tabular}{|c|l|}
\hline Value & \multicolumn{1}{c|}{ Description } \\
\hline 0 & Dt is within specified range \\
\hline 1 & Dt is 0, duplicate sample \\
\hline 2 & Dt is less than specified lower limit \\
\hline 4 & Dt is greater than specified upper limit \\
\hline
\end{tabular}


Finally, the table below specifies the qc_time limits used for the MWR datastream.

Table 9. Limits for Time

\begin{tabular}{|l|c|c|}
\hline Datastream & $\begin{array}{c}\text { Lower } \\
\text { Limit }\end{array}$ & $\begin{array}{c}\text { Upper } \\
\text { Limit }\end{array}$ \\
\hline mwrlos & 20 & 39 \\
\hline
\end{tabular}

\subsubsection{Dimension Variables}

Table 10. Dimension Variables

\begin{tabular}{|l|l|l|}
\hline Variable Name & \multicolumn{1}{|c|}{ Quantity Measured } & \multicolumn{1}{c|}{ Unit } \\
\hline base_time & Base time in Epoch & seconds \\
\hline lat & north latitude & Degrees \\
\hline lon & east longitude & degrees \\
\hline alt & altitude & meters above Mean Sea Level \\
\hline
\end{tabular}

\subsection{Annotated Examples}

This section is not applicable to this instrument.

\subsection{User Notes and Known Problems}

Positive "spikes" are produced in the measurements during preventative maintenance due to water used to clean the teflon window.

\subsection{Frequently Asked Questions}

How should we use the QC flags (qcmin, qcmax, qcdelta)?

\section{Do we disregard suspicious data?}

Precipitable water vapor (PWV) and liquid water path (LWP) that exceed the maximum should be eliminated - these usually indicate rain. PWV below zero is unphysical and arises during rain because of the opposite signs of the retrieval coefficients. Negative LWP is OK as long as it is within or close to the RMS uncertainty in the retrieval. The RMS uncertainties in the PWV and LWP are included in the meta data:

- vapor_retrieval_rms_accuracy[cm] $=$ “0.057881” ; <--for December

- liquid_retrieval_rms_accuracy[cm] = “0.003083”; <--for December. 


\section{Why are "qcmax" flags not completely coincident with the weather log reports of rain?}

The qcmax flag for liquid is raised when the retrieved liquid water exceeds $1 \mathrm{~cm}$. Such a value is not possible--it indicates a serious failure of the retrieval, most likely due to water standing on the instrument. There are two reasons why this may not be completely coincident with weather log reports of rain. First, the operators are only onsite from 8 am to $5 \mathrm{pm}$ local time at the central facilities; if it rains when the operators aren't there, no log entry is made. Second, the problem can arise from standing water, not just rainfall; there is some time between the end of the rainfall and the evaporation of the water from the teflon window which covers the mirror on the instrument. So, the operators could report that the rain has stopped but the microwave radiometer window is still wet and thus still reporting invalid data.

\section{Can we use the data when there are long periods of "qcmin” flags for liquid?}

Yes, you can use the data. Actually, liquid values that are negative but within the RMS-accuracy of the retrieval of zero may be considered equal to zero, which is the physically plausible lower bound.

\section{When the weather log reports fog, is it possible that the microwave window gets covered with dew and leads to bad data even though no rain is reported?}

Dew has a fairly distinct signature - a smooth hump - in the retrieved vapor and liquid as well as in the underlying brightness temperatures. This is often seen just at or before dawn, however, it usually goes away before the operators would have reported to the site. (This assessment is borne out by the surface station data which indicated that the dew point was within the sensor accuracy of the ambient temperature at about the time when the "hump" first appeared.) For example, on one occasion the operators reported heavy ground fog at 1400 GMT (8 am local time) and the instrument showed 85-90 microns of liquid. I'd say the two were consistent.

The instruments are equiped with an "anti-dew" system that is comprised of a continuous fan and a 500-750 W heater controlled by a moisture sensor mounted on top of the instrument. Normally, the fan blows ambient air over the Teflon window to keep it clear of dust. During condensing or precipitating conditions the heater turns on to prevent the formation of dew or the settling of fog on the window as well as to promote the evaporation of rain and snow. The condition of the heater (ON/OFF) is indicated in the netCDF files by the wet_window variable.

This system seems to work quite well but the sensitivity of the heater needs to be maintained. Because it is a resistive element, it is somewhat temperature dependent, so it periodically triggers unnecessarily on cold nights. Although this doesn't affect the PWV or LWP measurements, it does cause some confusion when using the wet_window data as an indication of rain or dew or fog.

The MWRs have been retrofitted with new blowers that have greater air flow and heater circuitry that is less sensitive to ambient temperature. 


\section{When should we call the liquid water path zero (i.e. what is the noise level)?}

\section{Why do we see significant $\left(+/-30 \mathrm{~g} / \mathrm{m}^{3}=+/-0.03 \mathrm{~mm}\right)$ positive/negative values of the liquid water path when the sky is clear according to the ceilometer?}

The noise level is very low: $0.003 \mathrm{~mm}=0.0003 \mathrm{~cm}$ RMS. The problem is in the retrieval uncertainty. Statistical retrieval is essentially a multiple linear regression. Any regression will have a residual error. In the LWP retrieval the residual error or "theoretical accuracy" is $0.03 \mathrm{~mm}$ (RMS), 10 times the sensitivity or noise limit. So a value of LWP that is $+/-0.03 \mathrm{~mm}$ of zero could be clear sky.

The real problem here is that the mean radiating temperature, $\mathrm{T}_{\mathrm{mr}}$, of the atmosphere, which is determined at the time the retrieval coefficients are computed, is assumed to only vary monthly with the retrieval coefficients. The truth is that $\mathrm{T}_{\mathrm{mr}}$ varies diurnally - enough to cause the zero LWP to vary in a most annoying fashion within the uncertainty bounds of the retrieval.

\section{How can we correct calibration problems that affect the values of liquid water path?}

The retrieval of PWV and LWP is based on a weighted difference of the optical thicknesses of the two channels. (The weights are the retrieval coefficients.) Because the retrieval coefficients are determined by linear regression over a climatological range of likely conditions, they implicitly assume the mean conditions (e.g. mean radiating temperature, mean cloud liquid water temperature in the case of LWP). The farther the actual conditions are from the mean (due to diurnal and synoptic variations that the retrieval does not account for), the more error in the retrieval. Clear sky conditions are far from the mean LWP, and so they have a larger uncertainty than cloudy conditions that may be very close to the average. Calibration issues aside, the clear sky LWP may be wrong but the cloudy sky LWP may be very close to correct, so subtracting the clear sky offset from all values of LWP is not an optimal solution.

With respect to calibration errors, the problem is that the calibration value, the "noise injection temperature" affects the slope of the calibration (K/count) so that an error in the calibration really affects the scale rather than the offset of the brightness temperatures, but because the retrieved values result from the difference of the two channels (which are weighted differently) it can look like there is an offset in LWP for clear sky conditions.

The only good way to fix calibration errors is to reprocess the data to fix the brightness temperatures, then reapply the retrievals.

\section{What is a reasonable maximum liquid water path?}

Suppose the cloud averages $1 \mathrm{~g} / \mathrm{m}^{3}$ of liquid water and is $1 \mathrm{~km}$ thick. Then the LWP would be $10^{* *}-6 \mathrm{~g} / \mathrm{cm}^{3} \times 10^{* * 5} \mathrm{~cm}=0.1 \mathrm{~g} / \mathrm{cm}^{2}=0.1 \mathrm{~cm}=1 \mathrm{~mm}$.

Thus, values above, say, $3 \mathrm{~mm}$ would be rare; such high values would probably be accompanied by rain and thus not measured anyway. 


\section{Why do we see occasional spikes way over $3 \mathrm{~mm}$ in the liquid water path data?}

Two events cause the LWP to exceed $1 \mathrm{~mm}$ (or $3 \mathrm{~mm}$ ). The first is rain or melting snow. The second is condensation (dew). A rule of thumb Ed Westwater (NOAA/ETL) uses is brightness temperatures over $100 \mathrm{~K}$ aren't generally reliable (i.e. the optical depth can't get that large without precipitation or condensation on the Teflon window.) This rule is used to set the upper limit for brightness temperatures, i.e. when the brightness temperatures exceed $100 \mathrm{~K}$, a flag is set in the netCDF data file.

\section{Are the data from the MWRs independent of the radiosondes?}

No, not entirely. The retrievals are based on NWS radiosonde data from 1994-1999.

\section{Are the tuning functions still used?}

No. Use of the so-called tuning functions was discontinued on 6 April 1996. The tuning functions were removed from the SGP CF MWR data that were collected between 950101 - 960409. Data collected before this date have already had these removed by Jim Liljegren, while data after this time window never had the tuning functions applied.

At the time, it was commonly held that the sondes represented "ground truth" and that the "tuning functions” (i.e. regressions of model-calculated vs. measured brightness temperatures) accounted for errors in the microwave absorption model upon which the retrievals were based. Jim Liljegren and Barry Lesht have since determined that the variation in the sonde calibration explains the differences between the model calculations and the microwave radiometric measurements. By removing the tuning functions, the PWV and LWP retrieved from the microwave radiometer are independent of the radiosondes.

\section{What were the tuning functions?}

The tuning functions linearly relate model-calculated microwave brightness temperatures (using radiosonde data) to brightness temperatures measured with a microwave radiometer. These were needed to account for imperfections in the microwave absorption model used to develop the retrievals which relate precipitable water vapor and liquid water path to the microwave brightness temperatures. The tuning functions should be independent of the instrument and of the location - they should depend only on the microwave absorption model used in the calculations.

\section{How were the tuning functions determined?}

After each sonde launch, the model which computes the integrated vapor from the sonde as well as the microwave brightness temperatures is run automatically by the data system. Jim Liljegren collected all of these modeled and measured brightness temperatures between Oct. 92 and Dec. 93, selected those for which the sky was clear (that is, for which the RMS variation in the liquid-sensing channel brightness temperature was less than $0.4 \mathrm{~K}$ ) and calculated a regression for each channel. 


\section{What changes were made to the data ingest in October $1998 ?$}

The MWR software was revised to provide additional functionality as described below.

1. Faster sampling rate: Standard line-of-sight (LOS) observations can now be acquired at 15-second intervals vs. 20-second intervals previously. (The standard LOS cycle is comprised of one sky sample per blackbody sample and gain update.)

2. More flexible sampling strategy: Multiple sky observations can be acquired during a LOS cycle, up to 1024 per gain update. This permits sky samples to be acquired at intervals of 2.67 seconds for improved temporal resolution of cloud liquid water variations and better coordination with the millimeter cloud radar during IOPs.

3. Separation of zenith LOS observations from tipping curve (TIP) data: When the radiometer is in TIP mode, the zenith LOS observations are now extracted, the PWV and LWP computed and reported separately in the output file. This eliminates the periods of missing LOS data during calibration checks/updates.

4. Automatic self-calibration: The software now permits the calibration to be updated at specified intervals or continuously.

To ingest the new format of the raw data, significant changes were made to the MWR Data Object Design.

\section{Why are there anomalies in the data near local solar noon?}

These anomalies are due to the sun in the field of view of the radiometer. They occur near the equinoxes at TWP around noon in both TIP and LOS modes and at SGP near sunrise and sunset in east-west tip curve data.

\section{Why are there spikes in the data from November 1999 to July $2002 ?$}

The intermittent spikes in the LWP and PWV data were caused by the occurrence of blackbody signals (in counts) that were half of those expected, yielding negative sky brightness temperatures. This problem was due to some component of the Windows98 configuration that conflicted with the DOS-based MWR program or affected the serial port or the contents of the serial port buffer. It was finally corrected by upgrading the MWR software with a new Windows-compatible program. 


\section{Data Quality}

\subsection{Data Quality Health and Status}

The following links go to current data quality health and status results.

- $\quad$ DQ HandS (Data Quality Health and Status)

- $\quad$ NCVweb for interactive data plotting using.

The tables and graphs shown contain the techniques used by ARM's data quality analysts, instrument mentors, and site scientists to monitor and diagnose data quality.

\subsection{Data Reviews by Instrument Mentor}

Data quality control procedures for this system are mature. On a weekly basis, the instrument mentor produces and inspects plots of the precipitable water vapor (PWV) and liquid water path (LWP) versus time. The base level of LWP is evaluated for clear sky episodes and the PWV estimates are compared to those from the BBSS. DQRs are submitted when needed, and a summary report of data quality is sent monthly to the SGP site scientist team.

\subsection{Data Assessments by Site Scientist/Data Quality Office}

All DQ Office and most Site Scientist techniques for checking have been incorporated within DQ HandS and can be viewed there.

\subsection{Value-Added Procedures and Quality Measurement Experiments}

Many of the scientific needs of the ARM Program are met through the analysis and processing of existing data products into "value-added" products or VAPs. Despite extensive instrumentation deployed at the ARM CART sites, there will always be quantities of interest that are either impractical or impossible to measure directly or routinely. Physical models using ARM instrument data as inputs are implemented as VAPs and can help fill some of the unmet measurement needs of the program. Conversely, ARM produces some VAPs not in order to fill unmet measurement needs, but instead to improve the quality of existing measurements. In addition, when more than one measurement is available, ARM also produces "best estimate” VAPs. A special class of VAP called a Quality Measurement Experiment (QME) does not output geophysical parameters of scientific interest. Rather, a QME adds value to the input datastreams by providing for continuous assessment of the quality of the input data based on internal consistency checks, comparisons between independent similar measurements, or comparisons between measurement with modeled results, and so forth. For more information see, see the VAPs and QMEs web page and specifically:

- $\quad$ MWR PROF: Retrievals of water vapor, liquid water, and temperature profiles from a suite of ground-based instruments.

- $\quad$ LSSONDE: Radiosonde profiles, where the moisture profile is scaled to match the MWR's total precipitable water vapor. 
- $\quad$ QME MWR PROF: Comparisons of retrieved water vapor and temperature profiles from MWR PROF with radiosonde profiles.

- $\quad$ QME MWR/LBL: Comparisons of observed versus calculated microwave radiance at two frequencies.

- $\quad$ QME MWR COL: Comparisons of the MWR with an instrument performance model.

\section{Instrument Details}

\subsection{Detailed Description}

\subsubsection{List of Components}

Radiometrics WVR-1100 Radiometer

Radiometrics dew blower/heater/rain sensor assembly

Radiometrics tripod or quadrapod and tribrach leveling base

Small form factor computer

AC power cable for radiometer

AC power cable for heater

Serial communications cable

\subsubsection{System Configuration and Measurement Methods}

The water vapor radiometer receiver is composed of a gaussian optical antenna, a noise diode injection device, a dual junction isolator, a balanced mixer, an IF amplifier, a detector/video amplifier, and two Gunn diode oscillators (Figure 1).

The receiver accepts input power from the antenna and supplies a voltage proportional to antenna temperature (plus antenna noise) via a square law detector to the radiometer voltage-to-frequency converter on the microprocessor (digital) board. Receiver frequency selection is accomplished by alternately powering the 23.8 and $31.4 \mathrm{GHz}$ Gunn diode local oscillators. Brightness temperature calibration is provided by a noise source injected at the input (added to antenna temperature).

The Gunn diode oscillators and noise source are powered by the radiometer analog board and controlled by the radiometer digital board.

The MWR uses low noise, low power IF amplifiers. The receiver is linear with antenna power over a range of the sky and calibration observables. The receiver is thermally stabilized to ensure stability of the mixer and the noise diode and Gunn diode output and frequency.

The sky brightness temperature is measured in the following manner: The small-angle receiving cone of the gaussian-lensed microwave antenna is steered with a rotating flat mirror. Both the 23.8-GHz and 31.4-GHz waveband signals are transmitted through a single waveguide into an isolator and into the 
mixer section. Output from one of two Gunn diodes is injected into the local oscillator port of the mixer. The resultant IF signal is amplified, filtered to yield a $400-\mathrm{MHz}$-wide, dual sideband signal, detected, amplified again, and converted by a voltage-to-frequency converter.

Zero crossings of this signal are counted, yielding the raw data in counts. Counts are then converted to brightness temperature through algorithms in the FORTRAN program. Water vapor, liquid water, and phase path delay are calculated using site-specific retrieval coefficients read from the configuration file.

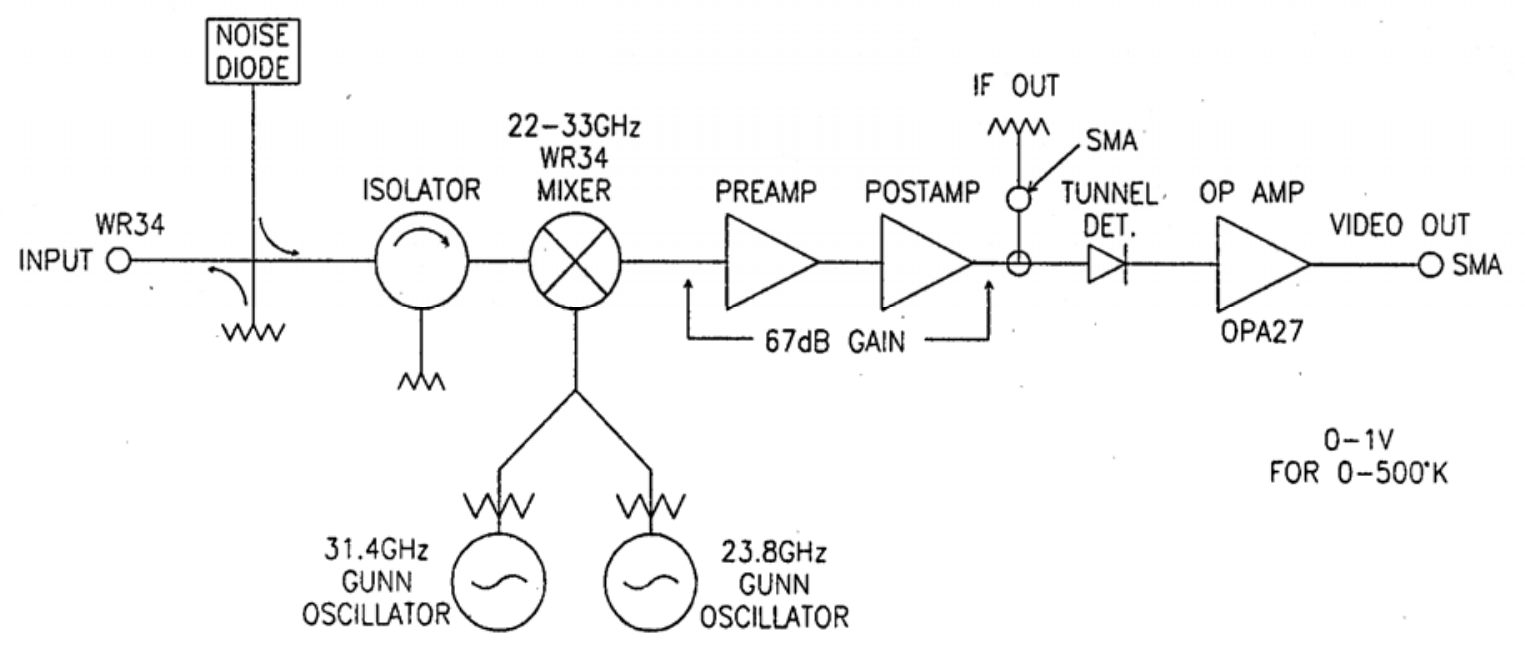

Figure 1. Radiometer receiver block diagram

\subsubsection{Specifications}

Table 11. Instrument Specifications

\begin{tabular}{|l|l|}
\hline \multicolumn{1}{|c|}{ Parameter } & \multicolumn{1}{c|}{ Value } \\
\hline Sample Time & User Selectable; Nominally 20 s in LOS Mode, $58 \mathrm{~s}$ in TIP Mode \\
\hline Accuracy & $0.3 \mathrm{~K}$ \\
\hline Resolution & $0.25 \mathrm{~K}$ \\
\hline Radiometric range & 0 to $700 \mathrm{~K}$ \\
\hline Operating range & -20 to $+50^{\circ} \mathrm{C}$ \\
\hline Power requirements & $120 \mathrm{~W}$ maximum \\
\hline Voltage requirements & 90 to 130 or 180 to $260 \mathrm{VAC} ; 50$ to $440 \mathrm{~Hz}$ \\
\hline Output & ASCII data files to laptop computer via $\mathrm{RS}-232$ at 9600 baud \\
\hline Dimensions & $50 \times 28 \times 76 \mathrm{~cm}$ \\
\hline Weight & $17 \mathrm{~kg}$ \\
\hline Angular coverage & all sky \\
\hline Pointing slew rate & $3^{\circ} / \mathrm{second}$ azimuth; $>90^{\circ} / \mathrm{second}$, elevation \\
\hline Field of view & $5.9^{\circ}$ at $23 . \mathrm{GHz}, 4.5^{\circ}$ at $31.4 \mathrm{GHz}$ (full width at half maximum) \\
\hline
\end{tabular}




\subsection{Theory of Operation}

The instrument itself is essentially a sensitive microwave receiver. That is, it is tuned to measure the microwave emissions of the vapor and liquid water molecules in the atmosphere at specific frequencies. For a specific frequency, n, the amount of microwave radiation observed by a radiometer at the earth's surface looking directly upward can be expressed as:

$$
\mathrm{I}=\mathrm{I}_{\mathrm{C}} \mathrm{e}^{-\mathrm{t}(0, \infty)}+\int(0, \infty)\left\{\mathrm{B}[\mathrm{T}(\mathrm{z})] \mathrm{rke}^{-\mathrm{t}(0, \mathrm{z})} \mathrm{dz}\right\}
$$

The first term represents the amount of cosmic (i.e. extraterrestrial) radiation entering at the top of the atmosphere $I_{c}$ that reaches the radiometer. The exponential decay factor accounts for attenuation of the cosmic radiation by the intervening atmosphere; $t$ is the optical thickness:

$$
\mathrm{t}(0, \mathrm{z})=\int(0, \mathrm{z})\{\mathrm{r}(\mathrm{z}) \mathrm{k}(\mathrm{z}) \mathrm{dz}\}
$$

where $\mathrm{r}$ is the density [mass per volume] or [number per volume] and $\mathrm{k}$ is the extinction coefficient [area per mass] or [area per number]. It is highly dependent on frequency. (Note that extinction is the sum of absorption plus scattering; however, because scattering is negligible in the microwave region of the electro-magnetic spectrum - except during heavy rain - $\mathrm{k}$ can be taken as the absorption coefficient alone.) The physical significance of $t$ is that it represents an "effective thickness" of the atmosphere for a particular frequency: $t$ will be large (and the attenuation $e^{-t}$ great) when either $\mathrm{z}, \mathrm{r}$ or $\mathrm{k}$ is large. Put another way, if $r$ and $k$ are large enough that a very small value of $z$ will still cause $e^{-t}=1$, then the region is said to be "optically thick" - one cannot "see" very far into it. On the other hand, if $r$ and k are sufficiently small, a very large value of $\mathrm{z}$ will be required to produce $\mathrm{e}^{\mathrm{t}}=1$ and the region is said to be "optically thin" - one can "see” a large distance at this frequency.

The second term in Eq. (1) represents the sum of the contributions from the atmosphere along the line-ofsight (i.e., the path). $\mathrm{B}[\mathrm{T}(\mathrm{z})]$ is the Planck function which describes the blackbody emission from the molecules at height $\mathrm{z}$ (which are at a temperature $\mathrm{T}(\mathrm{z})$ ). The product rk is the amount of blackbody radiation that is emitted (i.e., not re-absorbed) by the molecules in the layer. The factor $\mathrm{e}^{-\mathrm{t}}$ accounts for the attenuation by the atmosphere between the source molecules and the microwave radiometer antenna.

In the microwave region, the Planck function may be expressed as:

$$
\mathrm{B}(\mathrm{T})=2 \mathrm{KTc} / \mathrm{l}^{4}
$$

where $\mathrm{K}$ is Boltzmann's constant, $\mathrm{c}$ is the speed of light and $\mathrm{l}$ is the wavelength of the radiation. We can rearrange this expression to define the equivalent blackbody brightness temperature: $T_{B}=I 1^{4} / 2 K c$. If Eq. (1) is divided through by $2 \mathrm{Kc} / \mathrm{l}^{4}$ then:

$$
\mathrm{T}_{\mathrm{B}}=\mathrm{T}_{\mathrm{c}} \mathrm{e}^{-\mathrm{t}(0, \infty)}+\int(0, \infty)\left\{\mathrm{T}(\mathrm{z}) \mathrm{r}(\mathrm{z}) \mathrm{k}(\mathrm{z}) \mathrm{e}^{-\mathrm{t}(0, \mathrm{z})} \mathrm{dz}\right\}
$$


where $T_{C}=2.75$ kelvins. To actually calculate $T_{B}$, the atmosphere is divided into a number of layers $\mathrm{N}$ which are considered isothermal:

$$
\mathrm{T}_{\mathrm{B}}=\mathrm{T}_{\mathrm{C}} \mathrm{e}^{-\mathrm{t}(0, \infty)}+\sum(\mathrm{i}, \mathrm{N}) \mathrm{T}_{\mathrm{i}} \int\left(\mathrm{z}_{\mathrm{i}}, \mathrm{Z}_{\mathrm{i}+1}\right)\left\{\mathrm{r}(\mathrm{z}) \mathrm{k}(\mathrm{z}) \mathrm{e}^{\mathrm{t}(\mathrm{(}, \mathrm{z})} \mathrm{dz}\right\}
$$

If $\mathrm{N}=1$ (i.e., the entire atmosphere is taken to be isothermal), then:

$$
\begin{aligned}
\mathrm{T}_{\mathrm{B}} & =\mathrm{T}_{\mathrm{C}} \mathrm{e}^{-\mathrm{t}(0, \infty)}+\mathrm{T}_{\mathrm{MR}} \int(0, \infty)\left\{\mathrm{r}(\mathrm{z}) \mathrm{k}(\mathrm{z}) \mathrm{e}^{-\mathrm{t}(0, \mathrm{z})} \mathrm{dz}\right\} \\
& =\mathrm{T}_{\mathrm{C}} \mathrm{e}^{-\mathrm{t}}+\mathrm{T}_{\mathrm{MR}}\left[1-\mathrm{e}^{-\mathrm{t}}\right]
\end{aligned}
$$

where $t=t(0, \infty)$, the total zenith absorption, and $T_{M R}$ is the mean radiating temperature of the atmosphere at this frequency. (In general, there is a different $T_{M R}$ for each frequency). Equation (6) is the "brightness temperature equation;” it is used to relate the observed emission $\mathrm{T}_{\mathrm{B}}$ to the absorption:

$$
\mathrm{t}=\ln \left(\mathrm{T}_{\mathrm{MR}}-\mathrm{T}_{\mathrm{c}} / \mathrm{T}_{\mathrm{MR}}-\mathrm{T}_{\mathrm{B}}\right)
$$

$\mathrm{V}$ and $\mathrm{L}$ are then derived by relating them to the microwave absorption $\mathrm{t}$ :

$$
\begin{gathered}
\mathrm{t}=\mathrm{t}_{\mathrm{dry}}+\mathrm{t}_{\mathrm{vap}}+\mathrm{t}_{\text {liq }} \\
=\mathrm{t}_{\text {dry }}+\mathrm{k}_{\mathrm{V}} \mathrm{V}+\mathrm{k}_{\mathrm{L}} \mathrm{L}
\end{gathered}
$$

$\mathrm{t}_{\mathrm{dry}}$ is due to the (approximately constant) emission of $\mathrm{O}_{2}$ molecules; $\mathrm{k}_{\mathrm{V}}$, and $\mathrm{k}_{\mathrm{L}}$ are calculated from climatology with sufficient accuracy to determine t.

Observations of $\mathrm{T}_{\mathrm{B}}$ at a vapor sensitive frequency $(23.8 \mathrm{GHz}$ ) and a liquid sensitive frequency (31.4 GHz) yield two linear equations which can be solved for the two unknowns, V and L. Note that the vapor sensitive frequency is chosen such that $\mathrm{k}_{\mathrm{V}}$ is not dependent on pressure - and thus not dependent on height. The unknowns $\mathrm{V}$ and $\mathrm{L}$ can be represented in terms of the optical depths:

$$
\mathrm{V}=\mathrm{a}_{\mathrm{o}}+\mathrm{a}_{1} \mathrm{t}_{\mathrm{v}}+\mathrm{a} 2 \mathrm{t}_{\mathrm{l}}
$$

where the variables in italics are climatological mean values and the $\mathrm{a}_{\mathrm{i}}$ are determined through a linear regression (i.e., they are the "regression coefficients"). A similar expression can be written for the total liquid water, $\mathrm{L}$.

\subsection{Calibration}

\subsubsection{Theory}

When brightness temperature measurements are taken, the calibrated noise diode is automatically used to inject a known temperature into the antenna wave guide to determine gain, and offset is determined by observing the internal blackbody with the radiometer antenna. This eliminates error due to any drift in the microwave receiver. 


\section{Background}

The electrical output of the radiometer $\mathrm{V}$ in volts or digital counts is linearly related to the equivalent microwave brightness temperature TB:

$$
\mathrm{T}_{\mathrm{B}}=\mathrm{T}_{\mathrm{ref}}+\left(\mathrm{V}-\mathrm{V}_{\mathrm{ref}}\right) / \mathrm{G}
$$

Here $\mathrm{T}_{\text {ref }}$ is the reference temperature of the internal blackbody target and $\mathrm{V}_{\text {ref }}$ is the corresponding radiometer signal. $\mathrm{G}$ is the gain of the system in units of volts (or digital counts) per kelvin. One way to determine the gain $\mathrm{G}$ is through the use of tip-curves.

The ARM radiometers use a reverse-biased diode which injects broadband microwave energy ("noise”) directly into the waveguide when it is switched on, causing the signal output of the radiometer to increase by $\mathrm{V}_{\text {nd. }}$. The output of the noise diode is determined during the tip-curve procedure by pointing the elevation mirror at the reference blackbody target and measuring the radiometer output with the noise diode on and off:

$$
\mathrm{V}_{\text {nd }}=\mathrm{V}_{\text {ref }+ \text { nd }}-\mathrm{V}_{\text {ref. }}
$$

This "noise diode" output is calibrated from the tip-curve-derived gain to yield the noise injection temperature:

$$
\mathrm{T}_{\mathrm{nd}}=\mathrm{V}_{\mathrm{nd}} / \mathrm{G}
$$

which is useful because it is nearly insensitive to changes in ambient temperature even though $V_{\text {nd }}$ and $G$ are strong functions of temperature.

Because the instantaneous output of the noise diode represents a random process having a Gaussian distribution, the results of many tip-curves ( $>500)$ are used to compute $G$ and $V_{\text {nd }}$ and thus $T_{\text {nd. }}$.

Once calibrated, the system gain can be determined using the noise diode by viewing the blackbody target and measuring the change in the radiometer output due to switching on the noise diode, $G=\left(V_{\text {ref }+ \text { nd }}\right.$ $\mathrm{V}_{\text {ref }} / \mathrm{T}_{\mathrm{nd}}$.

\section{Temperature Dependence of the Calibration}

The gain is very sensitive to the temperature of the radiometer components (i.e., the feed horn, waveguides, mixer, local oscillators, etc.). As a result, the stability of the gain is directly related to the thermal stability of the instrument. The microwave hardware in the ARM radiometers is mounted on a thick aluminum plate in an insulated enclosure and thermally stabilized to $\pm 0.25 \mathrm{~K}$. Even so, the slight variations in the gain (which is the slope of the calibration curve) that arise from these slight temperature variations must be accounted for because the sky brightness temperatures typically range from 10-80 K whereas the blackbody reference temperature is at ambient $(\sim 300 \mathrm{~K})$ so small errors in the gain will result in significant errors in the brightness temperature. Consequently, the tip-curve data are used to derive a linear relationship between the noise injection temperature and the ambient temperature (represented by the temperature of the blackbody target, $\mathrm{T}_{\text {ref }}$ ): 


$$
\mathrm{T}_{\text {nd }}=\mathrm{T}_{\text {nd }}(290 \mathrm{~K})+\mathrm{a}\left(\mathrm{T}_{\mathrm{ref}}-290\right)
$$

where a is the temperature coefficient which typically ranges from -0.08 to $0.08(\mathrm{~K} / \mathrm{K})$.

\subsubsection{Procedures}

\section{Tip Curves}

To perform a tip-curve calibration, measurements of optical thickness $t$ are required along paths at various elevation angles, a. If the atmosphere can be assumed to be horizontally homogeneous, then the optical thickness along a path at an angle a above the horizon is directly proportional to the optical thickness at the zenith:

$$
\mathrm{t}(\mathrm{m})=\mathrm{mt}(1)
$$

where $\mathrm{m}=1 / \sin (\mathrm{a})$ is the "air mass" (e.g., a line-of-sight path inclined at an angle of 30 degrees above the horizon or $\mathrm{m}=2$ traverses twice the mass of air as at 90 degrees or $\mathrm{m}=1$ ). The procedure is as follows:

1. Use the existing calibration as an approximation.

2. Use the approximate calibration and measure brightness temperatures at elevation angles corresponding to several different air masses. For ARM, the elevation angles are 19.5, 23.6, 30.0, 41.8, 90.0, 138.2, 150.0, 156.4, 160.5, and 90.0 which corresponds to $m=3.0,2.5,2.0,1.5,1.0$, 1.5, 2.0, 2.5, 3.0, and 1.0. Angles on both sides of zenith are used to ensure horizontal homogeneity.

3. Relate these brightness temperatures to optical thickness:

$$
\mathrm{t}(\mathrm{m})=\ln \left[\left(\mathrm{T}_{\mathrm{MR}}-\mathrm{T}_{\mathrm{c}}\right) /\left(\mathrm{T}_{\mathrm{MR}}-\mathrm{T}_{\mathrm{B}(\mathrm{m})}\right)\right]
$$

4. Fit a straight line to the optical thickness as a function of air mass. Since the absorption should be zero for $\mathrm{m}=0$ (no atmosphere), the intercept represents the error in the current calibration. If the correct brightness temperatures had been used the intercept would pass though the origin. Thus, the true zenith optical thickness $\mathrm{t}(1)$ is equal to the slope of the regression line.

Note that the quality of the fit indicates the degree to which the atmosphere is horizontally homogeneous. In the presence of clouds, for example, the tip-curve calibration method is not valid because the absorption is not linearly related to air mass. For ARM, the regression must account for at least $99.8 \%$ of the observed variance $\left(\mathrm{R}^{2}=0.998\right)$ to be considered valid. Angles on both sides of the zenith corresponding to the same air mass are used to assess horizontal homogeneity. 
5. The true zenith optical thickness $t 1$ is now used to compute the true zenith brightness temperature:

$$
\mathrm{T}_{\mathrm{B}(\text { zenith) }}=\mathrm{T}_{\mathrm{C}} \mathrm{e}^{-\mathrm{t} 1}+\mathrm{T}_{\mathrm{MR}}\left(1-\mathrm{e}^{-\mathrm{t} 1}\right)
$$

6. Now the gain can be computed:

$$
\mathrm{G}=\left(\mathrm{V}_{\text {zenith }}-\mathrm{V}_{\text {ref }}\right) /\left(\mathrm{T}_{\mathrm{B}(\mathrm{zenith})}-\mathrm{T}_{\text {ref }}\right)
$$

\section{Cryogenic Calibration}

The tip curves will determine the gain and offset of the radiometer and transfer this to a highly stable noise diode gain reference. Therefore, the MWR does not require cryogenic calibration. However, an external cold target is occasionally used to verify the calibration of the internal noise diode. The target consists of blackbody foam immersed in about 30 liters of liquid nitrogen contained in a polystyrene foam cooler. This provides a reference point in the vicinity of $77 \mathrm{~K}$ that can be known to about $0.3 \mathrm{~K}$ by a simple barometric pressure measurement.

\subsubsection{History}

The ARM MWRs are now able to calibrate themselves during clear sky periods, as described in the following book chapter: Liljegren, J.C. 1999. Automatic self-calibration of ARM microwave radiometers. Microwave Radiometry and Remote Sensing of the Earth's Surface and Atmosphere, eds. P. Pampaloni and S. Paloscia, pp. 433-443. VSP Press.

The calibration coefficients are found as time-dependent variables in the netCDF files. They are the noise injection temperatures at the nominal temperature (usually $290 \mathrm{~K}$ ), tnd23 and tnd31, and the temperature correction coefficients, tc23 and tc31.

\subsection{Operation and Maintenance}

\subsubsection{User Manual}

This section is not applicable to this instrument.

\subsubsection{Routine and Corrective Maintenance Documentation}

$\underline{\text { SGP Preventative Maintenance Procedure }}$

TWP Operating Procedure

NSA Preventative Maintenance Procedure Manual 


\subsubsection{Software Documentation}

Installation, Operation and Troubleshooting Guide for MWR.EXE: Software for ARM Microwave Water Radiometers.

ARM netCDF file header descriptions may be found at MWR Data Object Design Changes.

\subsubsection{Additional Documentation}

See Routine and Corrective Maintenance Documentation, Section 7.4.2.

\subsection{Glossary}

See the ARM Glossary at http://www.arm.gov/about/glossary.stm.

\subsection{Acronyms}

See the ARM Acronyms at http://www.arm.gov/about/glossary.stm.

\subsection{Citable References}

Braun, J., C. Rocken, and J. Liljegren. 2003. Comparisons of Line-of-Sight Water Vapor Observations Using the Global Positioning System and a Pointing Microwave Radiometer. Journal of Atmospheric and Oceanic Technology, 20, 606-612.

Cimini, D., E. Westwater, Y. Han, and S. Keihm. 2003. Accuracy of Ground-Based Microwave Radiometer and Balloon-Borne Measurements During the WVIOP2000 Field Experiment. IEEE Transactions of the Geosciences Remote Sensing 41:2605-2615.

Han, Y., and E. Westwater. 2000. Analysis and Improvement of Tipping Calibration for Ground-Based Microwave Radiometers. IEEE Transactions of the Geosciences Remote Sensing 38:1260-1276.

Liljegren, J.C. 1994. Two-channel microwave radiometer for observations of total column precipitable water vapor and cloud liquid water path. Fifth Symposium on Global Change Studies, pp. 262-269. January 23-28, 1994. American Meteorological Society, Nashville, Tennessee.

Liljegren, J.C., and B.M. Lesht. 1996. Measurements of integrated water vapor and cloud liquid water from microwave radiometers at the DOE ARM Cloud and Radiation Testbed in the U.S. Southern Great Plains. Presented at the IEEE International Geosciences and Remote Sensing Symposium (IGARSS). May 21-26, 1996, Lincoln, Nebraska.

Liljegren, J.C. 1999a. Automatic self-calibration of ARM microwave radiometers. Microwave Radiometry and Remote Sensing of the Earth's Surface and Atmosphere, eds. P. Pampaloni and S. Paloscia, pp. 433-443. VSP Press. 
Liljegren, J.C. 1999b. Observations of integrated water vapor and cloud liquid water at the SHEBA ice station. Microwave Radiometry and Remote Sensing of the Earth's Surface and Atmosphere, eds. P. Pampaloni and S. Paloscia, pp. 155-163. VSP Press.

Liljegren, J.C., E. Clothiaux, G. Mace, S. Kato, and X. Dong. 2001. A new retrieval for cloud liquid water path using a ground-based microwave radiometer and measurements of cloud temperature. Journal of Geophysical Research 106:14,485-14,500.

Lin, B., P. Minnis, A. Fan, J. Curry, and H. Gerber. 2001. Comparison of cloud liquid water paths derived from in situ and microwave radiometer data taken during the SHEBA/FIREFACE. Geophysical Research Letters 28:975-978.

Liou, Y.-A., Y-T. Teng, J. Liljegren, and T. Van Hove. 2001. Comparison of precipitable water observations in the near tropics by GPS, radiometer, and radiosondes. Journal of Applied Meteorology 4:5-15.

MacFarland S., and F. Evans. 2002. A Bayesian Algorithm for the Retrieval of Liquid Water Cloud Properties from Microwave Radiometer and Millimeter Radar Data. Journal of Geophysical Research (accepted).

Mattioli, V., E. Westwater, S. Gutman, and V. Morris. 2004. Forward Model Studies of Water Vapor using Scanning Microwave Radiometers, Global Positioning System, and Radiosondes during the Cloudiness Inter-Comparison Experiment. IEEE Transactions of the Geosciences Remote Sensing (in press).

Westwater, E., Y. Han, M. Shupe, and S. Matrosov. 2001. Analysis of integrated cloud liquid and precipitable water vapor retrievals from microwave radiometers during the Surface Heat Budget of the Arctic Ocean project. Journal of Geophysical Research 106:32,019-32,030.

Westwater, E., B. Stankov, D. Cimini, Y. Han, J. Shaw, B. Lesht, and C. Long. 2003. Radiosonde Humidity Soundings and Microwave Radiometers during Nauru99. Journal of Atmospheric and Oceanic Technology 20:953-971. 